\title{
ON THE IDENTITY OF THREE GENERA OF CAMBALOID MILLIPEDS FROM THE AUSTRALIAN REGION (SPIROSTREPTIDA)*
}

\author{
By RichaRd L. HofFMaN \\ Radford College, Radford, Virginia 24I4I
}

In his large and important paper "The Myriapoda of the Australian Region" R. V. Chamberlin (I920) described a great number of new genera and species of diplopods in very succinct terms and without a single illustration of the male genitalia. As a result the majority of these taxa have remained down to the present time as frustrating enigmata to other students of Diplopoda and have impeded the orderly development of classification in several orders of this class. Inasmuch as the material named by Chamberlin in this and many other papers is deposited in the Museum of Comparative Zoology, that institution has become something of a Mecca in recent years for diplopodologists who have visited it in search for the truth that lies concealed behind the veil of Chamberlinian descriptions.

On recently beginning a study of the world fauna of the milliped suborder Cambalidea, I was confronted by the fact that the 1920 paper contained the debut of I 3 new species and three new genera of cambaloids from Australia, New Zealand, Tasmania, and several Pacific island groups. An appeal to Dr. H. W. Levi resulted in the prompt and generous loan of typical material representing all three of the genera, and since some time may pass before completion of the general synopsis of the suborder, it seems desirable to place on record a short account of these taxa for the general benefit of others having occasion to work with the milliped fauna of the South Pacific area.

\section{Eumastigonus Chamberlin 1920}

Bull. M. C. Z., 64: 162. Type species, E. kaorinus Chamberlin, by original designation.

This genus, proposed for five new species from New Zealand, was compared only with Dimerogonus (Attems, 1903), from which it was said to differ "... in having the first legs of the male with strongly developed claws and otherwise also similar to the succeeding pairs." Material of the type species E. kaorinus could not be located at the M.C.Z. in I97I (possibly it was standing under a different name, as it was not unusual for Chamberlin to change his mind with-

*Manuscript received by the editor September 18, 1972 
out changing the original label), but the holotype of $E$. distinctior was made available. Chamberlin's account of the gonopods leaves no doubt that distinctior and kaorinus are congeneric and that the genus may be safely interpreted on the basis of a species other than its type.

Examination of the material of E. distinctior revealed that Chamberlin's verbal account of gonopod structure is fairly accurate. It also proved that he mistook the second pair of legs for the first, as will be evident from the drawing that I made (Fig. I) of the head and first segment. The first legs are in fact slightly reduced and partly concealed by the second, although this is no excuse for failure of the describer to look closely (particularly since at that time a number of cambaloids with diminutive first legs were known). The major stated distinguishing character of the genus is thus abolished, since the first pair of legs are really not much different from those of Dimerogonus, being small with transversely prolonged coxae and a four-jointed telopodite lacking a tarsal claw. Since the form of the first legs is almost invariably constant among cambaloid species having similar gonopods, I think it is reasonable to assume that the structure illustrated here is essentially the same as obtains in $E$. kaorinus, the type species.

The original illustrations of the type species of Dimerogonus, $D$. orophilus Attems (1903, pl. 7, figs. I-6) show that the first legs of the male are unusual in having the three basalmost segments broadly enlarged, twice or three times as wide as the small, short, distalmost three podomeres. This species likewise differs from E. kaorinus in gonopod structure. Dimerogonus, despite the considerable number of trans-Pacific species subsequently referred to it by divers authors, is unquestionably to be regarded as a so-far monotypic genus known only from the Blue Mountains of New South Wales. A second species, however, also originally included in Attems' concept of Dimerogonus, does show a striking similarity to $E$. distinctior. This species, D. insulanus Attems, agrees closely with distinctior in both gonopod structure and form of the first male legs; there is no doubt that the two species are congeneric as a comparison of my drawings (Figs. I-4) with Attems Figures 7-I 4 of his 1903 paper will show.

In 1944, K. W. Verhoeff noted that the great difference in form of the first male legs was sufficient basis for separating Attems' two species generically, and he proposed the name Insulocambala for insulanus. Since insulanus is manifestly congeneric with the type of Eumastigonus, and since the latter name has 24 years priority over 
Verhoeff's, it is apparent that Insulocambala must be considered a junior subjective synonym of Eumastigonus (NEW SYNONYMY!).

There is some doubt about the provenance of $E$. insulanus. Attems stated only "Stephens Island (Dr. Schauinsland coll. I $0^{*}$ )." It is known that Schauinsland did make collections along the coast of western North America, and there is a Stephens Island near Prince Rupert, British Columbia, which I judge is the implied type locality. But in view of the obvious congenericity of insulanus with the New Zealand species named by Chamberlin, it seems implausible to me that the type really originated in North America. I would rather prefer to suspect some mixup in labeling either by the collector or by Attems, and that the material really came from North Island, New Zealand. An alternative possibility is that specimens of a New Zealand species might have been incidentally introduced through commerce and become established. It would be a zoogeographic milestone if it were ever proven that a Eumastigonus is really endemic to Stephens Island.

\section{Eumastigonus distinctior Chamberlin 1920 Figures I-5}

Bull. M. C. Z., 64: 164. Holotype, ô, MCZ 4872, from Day's Bay near Wellington, North Island, New Zealand (W. M. Wheeler).

The first pair of legs of the male is somewhat reduced in size, with the coxae prolonged laterad. The podomeres distad to the prefemur are nearly as wide as long, and the tibiotarsus (Fig. I, tt) is apically rounded, without a claw. The anterior gonopods terminate distally in four processes, one of which represents the telopodite although I could not see a clear articulation with the coxa at its base. These processes are labeled $a, b$, and $c$, and the apex of the telopodite $d$, on the drawings. Process $a$ corresponds to what Chamberlin called the "distomesal process", $b$ to his "membranous lobe", and $c$ to his "pectinate lobe". From a caudomesal aspect (Fig. 2) it is evident that processes $b$ and $d$ form a sort of envelope in which the posterior gonopod can be accommodated. The prominent coxal flagellum, from which the generic name was derived, is apically penicillate. The

Figs. 1-5. Eumastigonus distinctior Chamberlin, from male holotype. Fig. 1. First pair of legs, gnathochilarium, and part of mandible, right side, aboral aspect. Fig. 2. Gonopods, oral aspect (left posterior gonopod not shown). Fig. 3. Right anterior gonopod, oblique caudomesal aspect. Fig. 4. Right anterior and posterior gonopods, lateral aspect (tracheocoxal muscle shown, others removed for clarity). Fig. 5. Apical third of right posterior gonopod, oral aspect, showing apparent basal articulation of anterior distal process (telopodite?). 


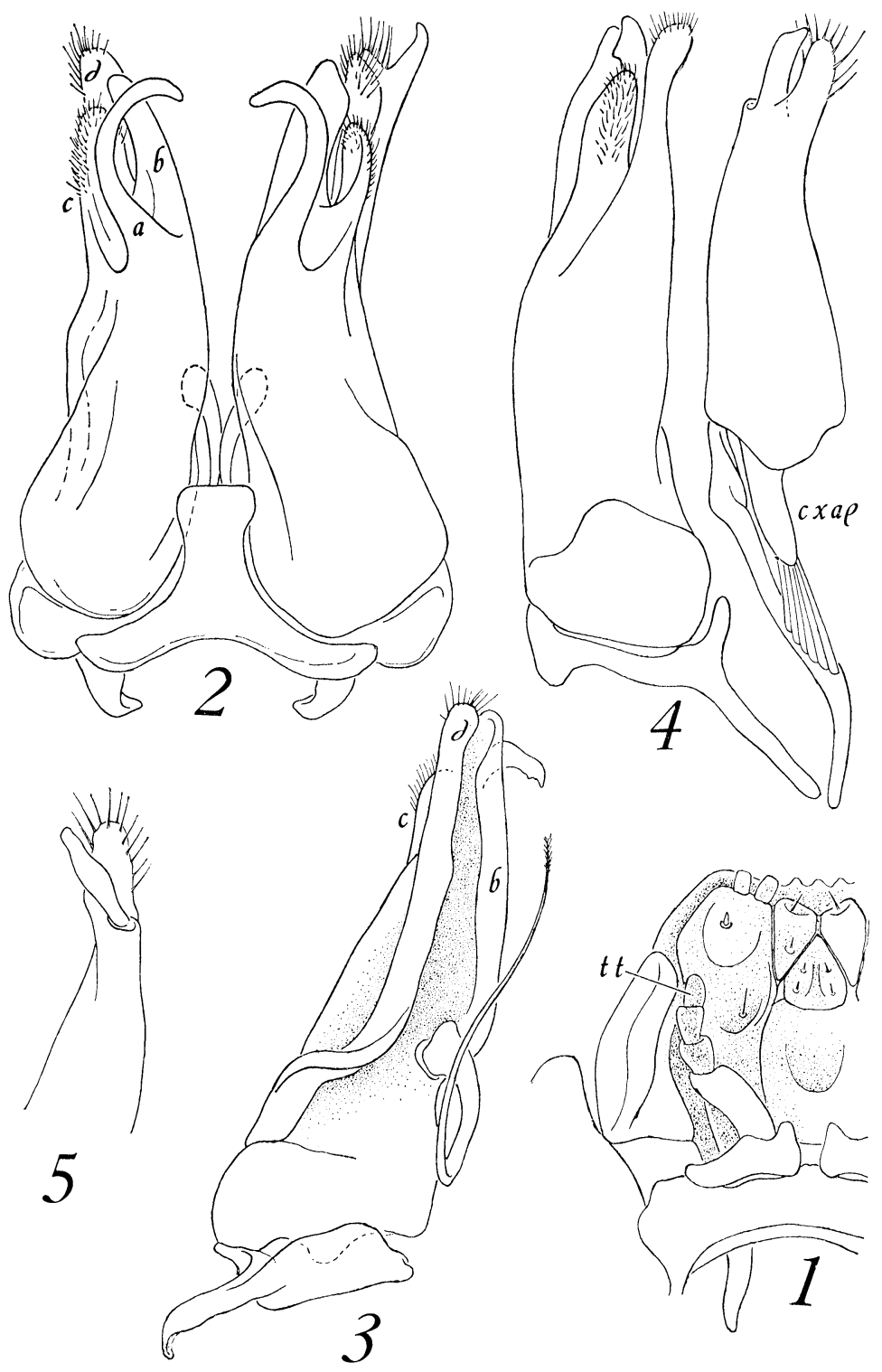


posterior gonopods (Fig. 3) are attached to a small but distinct sternum with unusually long tracheal apodemes; each is likewise proximally produced into a coxal apodeme (Cxap). The gonopod has the form of an elongate, flattened cylinder, distally narrowed, with a broadened setose lobe on the aboral side and a more slender anterior process; when seen in anterior aspect this latter structure appears to be basally articulated and may represent the telopodite remnant.

\section{Euethogonus Chamberlin 1920}

Bull. M. C. Z., 64: 166. Type species, E. hardyi Chamberlin, by original designation.

This monotypic genus was diagnosed as differing from Amastigogonus (Brolemann, I9I3) in having the first pair of male legs "normal" in appearance, with a tarsal claw and the basal segment not enlarged. The "pseudoflagellum" of the anterior gonopods was also said to be slender and acicular instead of "ribbon-shaped" as in Amastigogonus.

Dr. Levi sent the type material of $E$. hardyi for my examination. This revealed that, again, Chamberlin failed to look carefully at the specimen, in fact the head was still reflexed against the anterior legs and the latter could really not be seen clearly until head and collum had been displaced. Figure 6 shows what the first pair of legs looks like. They are essentially similar to those of Amastigogonus tasmanianus as shown in Fig. 32 of Brolemann's I9I3 paper on myriapods of the Australian Museum. The same may be said for the gonopods themselves. It is true that the "pseudoflagellum" (perhaps solenomerite would be a better term for the structure) is shorter than in A. tasmanianus, but in mesal aspect (Fig. 8) it could certainly be perceived as laminate and not needle-like. Since the type specimen of $E$. hardyi agrees so closely with Brolemann's account of tasmanianus in virtually every detail, I see no reason to separate the two species generically. Euethogonus is herewith regarded as a junior subjective synonym of Amastigogonus which has seven years priority. It is quite incredible that Chamberlin did not really try to examine the first male legs of hardyi, considering how closely it matched Brolemann's species in all other respects.

\section{Amastigogonus hardyi (Chamberlin), new combination} Figures 6-8

Euethogonus hardyi Chamberlin, 1920, Bull. M. C. Z., 64: 166. Holotype, ô, MCZ 4817, labeled only "Tasmania (G. H. Hardy)".

Amastigogonus nichollsii Verhoeff, 1944, Zool. Anz., 145: 44, figs. 1-7. 
Holotype, ô, Zool. Samml. Munchen, from "Tasmania am Mt. Nelson." NEW SYNONYMY!

Considering that Verhoeff's illustrations of $A$. nichollsii were drawn from slide preparations and mine from unmounted gonopods, I think it is evident that the two names cited above refer to the same species. The similarity in the first pair of legs extends down to the minute remnant of the tarsal claw. There are a few discrepancies regarding the relationships of the basalmost podomeres and the sternum, but again I suspect these are due to different methods of preparation (and observation). Verhoeff's Fig. 5 shows the sternum to be greatly reduced, with the coxae enlarged and broadly in contact medially. On the uncleared specimen of $A$. hardyi (see Fig. 6 herein) I could see no distinction in the basal sclerite and presumed that it is a syncoxosternum. Resolution of this point awaits examination of fresh material.

On the other hand, I can affirm general accord with Verhoeff's representation of the anterior gonopods. In making comparisons of these structures, it must be remembered that Verhoeff's Fig. I is made from the aboral aspect, my Fig. 7 from the oral side.

From the standpoint of phylogenetic significance, we may attach considerable importance to the presence of a "pseudoflagellum" on the telopodite of Amastigogonus and some other related cambaloids. As noted by Verhoeff, and likewise clearly evident in my figures 7 and 8 , this structure carries a distinct groove which originates in a fold at the base of the telopodite. I see no reason to doubt that it is morphologically homologous with the seminal groove of some other diplopods, notably spirostreptoids, and venture the opinion that the gonopod of Amastigogonus represents a primitive grade of organization on the line leading to the elaborately modified pattern met with in living Spirostreptidea. In the cambaloids of this type, since the groove-bearing unit is relatively small and subsidiary to the bulk of the telopodite, the name solenomerite can, I think, be justly applied from the standpoints of both function and homology.

\section{Nesocambala Chamberlin, I920}

Bull. M. C. Z., 64: 167. Type species, N. fijiana Chamberlin, by original designation.

As embodied in the formation of the name, Nesocambala inciuded three new species from the Fiji Islands and two from the Solomons. The diagnosis stated that these species collectively were similar to Agastrophus and Hypocambala in terms of labral teeth, but the remainder of the generic diagnosis failed to indicate whether the cited characters were differential or not. Examination of the type material 

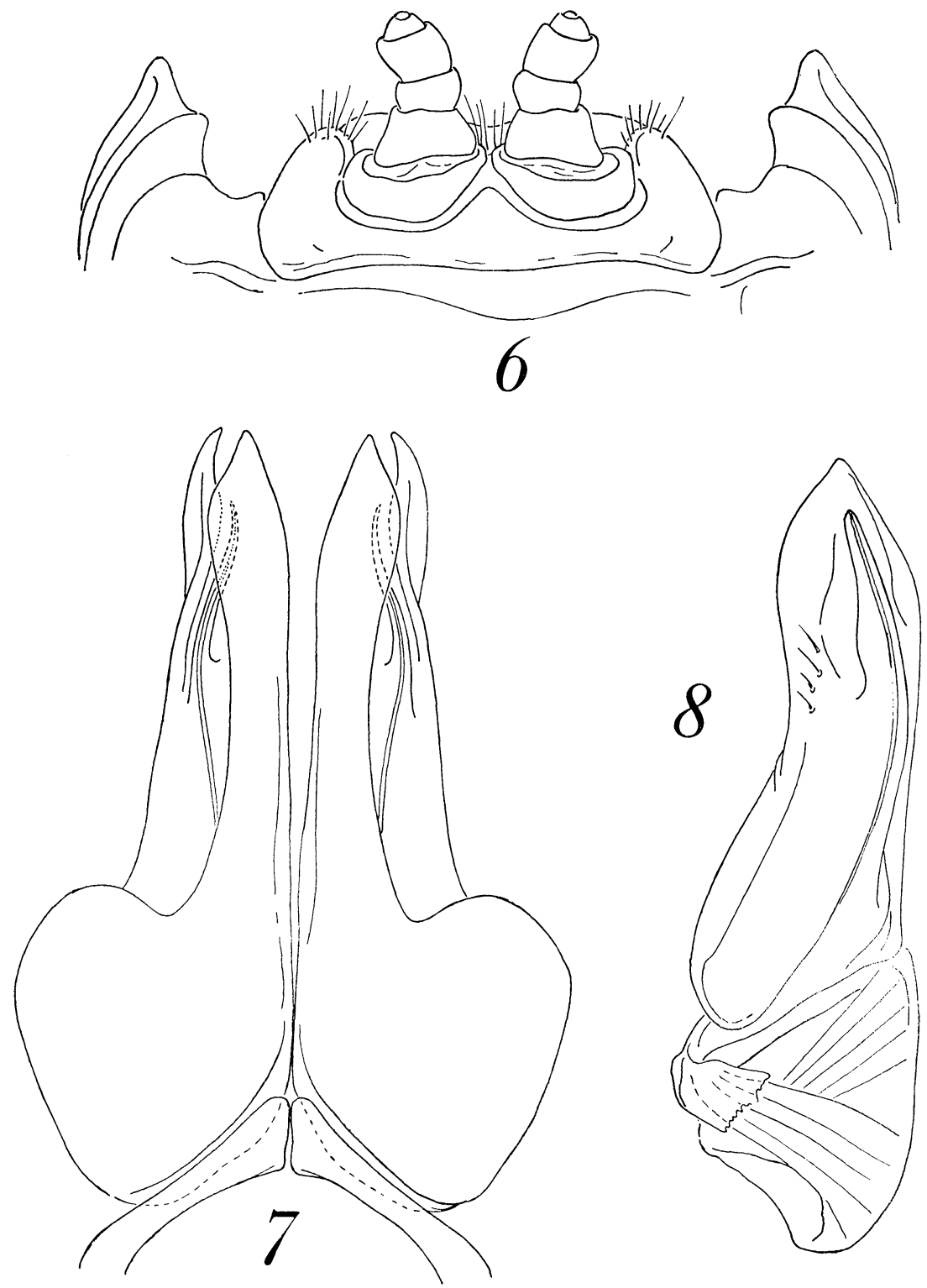

Figs. 6-8. Amastigogonus hardyi (Chamberlin), from male holotype. Fig. 6. First pair of legs, their sternal complex, and ventral ends of 2 nd pleurotergum, aboral aspect. Fig. 7. Anterior gonopods, oral aspect. Fig. 8. Right anterior gonopod, mesal aspect. 
of $N$. fijiana shows that this name is based on the same species as that described much earlier (1897) by Silvestri as Hypocambala helleri, and that in consequence, Nesocambala must be regarded as a junior subjective synonym of Hypocambala.

This was, of course, not the only time that Hypocambala has been re-named. Attems published the genus Agastrophus in 1900 for $A$. anguinus, a new species from the Seychelles, and Chamberlin proposed Trichonannolene in 1922 for T. guiananus from British Guiana. In 1938, Attems set up the name Ilyspasticus for his new $I$. gracilis from Indochina. Silvestri (1935) showed the synonymy of Agastrophus with Hypocambala, and Loomis \& Hoffman (1948) proposed the same disposition for Trichonannolene. Lastly, Jeekel (1963) gave a good historical summary of the entire situation, at which time he also brought Ilyspasticus into Hypocambala and presented a key to the known members of the genus. As he observed at that time "The genus Hypocambala forms a really coherent group, and distinction between the species is not always easy." The three generic junior synonyms were obviously based upon illusory characters, or outright mistakes.

Nesocambala fijiana Chamberlin, I920

Bull. M. C. Z., 64: 168. Holotype, ô, MCZ 4827, from Nadarivatu, Fiji

Islands (W. M. Mann).

As the type male of fijiana is clearly the same species as that described as Hypocambala helleri by Silvestri in 1897, Chamberlin's name thus becomes a junior subjective specific synonym (NEW SYNONYMY!). It is difficult to believe that he compared his material with Silvestri's well-illustrated paper, of which, however, he was obviously aware.

Being presently concerned only with the existing generic names for cambaloids, I have not examined types of the four other "species" of Nesocambala, but have very little doubt that they are based upon, for the most part, already described small cambaloids introduced by commerce into the southwest Pacific area.

\section{Summary}

The nomenclatorial changes suggested in this paper as a result of the examination of type material of three cambaloid genera set up by R. V. Chamberlin in 1920 are as follows:

I. Eumastigonus Chamberlin, 1920, is valid, with Insulocambala Verhoeff, I944, a junior synonym.

2. Euethogonus Chamberlin, 1920, is a junior synonym of Amastigogonus Brolemann, I913. 
3. Euethogonus hardyi Chamberlin, 1920, is referable to Amastigogonus as a valid species, with Amastigogonus nichollsii Verhoeff, 1944, regarded as a junior synonym.

4. Nesocambala Chamberlin, I920, is a junior synonym of Hypocambala Silvestri, I 897 .

5. Nesocambala fijiana Chamberlin, 1920 , is considered a junior synonym of Hypocambala helleri Silvestri, I897.

Attems, Carl

\section{REFERENCES}

1903. Beiträge zur Myriopodenkunde. Zool. Jahrb., Abt. Syst., 18(1) : 63-154, pls. 1-11.

BROLEMANN, H. W.

1913. The Myriapoda in the Australian Museum. Part II. - The Diplopoda. Rec. Australian Mus., 10 : 77-158, pls. 14-18.

Chamberlin, R. V.

1920. The Myriapoda of the Australian Region. Bull. Mus. Comp. Zool, $64(1): 1-269$.

JEEKEL, C. A. W.

1963. Diplopoda of Guiana, pts. 1-5, in Stud. Fauna Suriname, 4: 1-157.

Loomis, H. F., \& R. L. Hoffman

1948. Synonymy of various diplopods. Proc. Biol. Soc. Washington, 61: 51-54.

Silvestri, Fillipo

1897. Neue Diplopoden. Abh. Ber. Zool. Mus. Dresden, 6(9):1-23, pls. 1-3.

VERHOEFF, K. W.

1944. Zur Kenntnis der Cambaliden und über einige neue australische Formen derselben. Zool. Anz., 145: 27-45. 

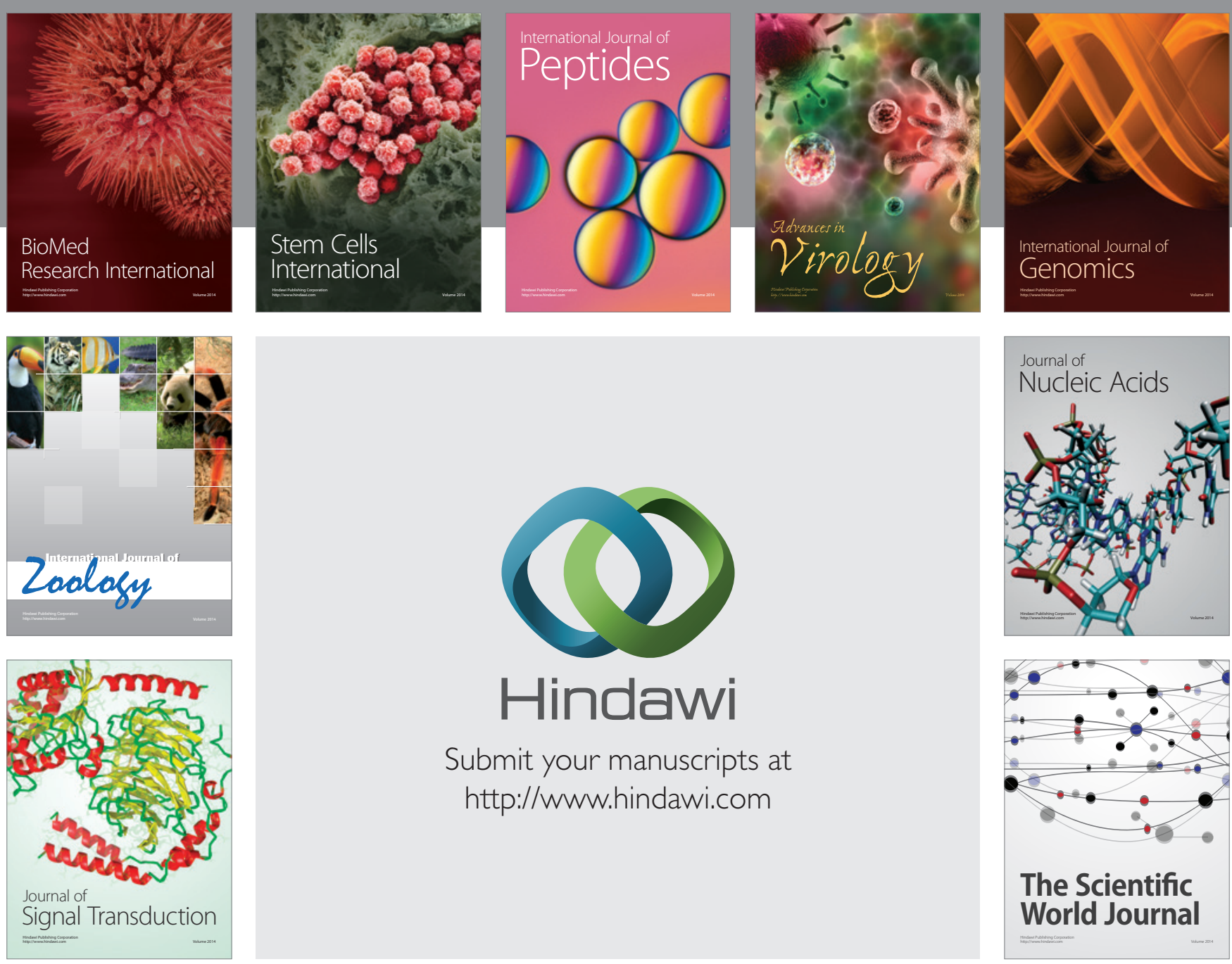

Submit your manuscripts at

http://www.hindawi.com
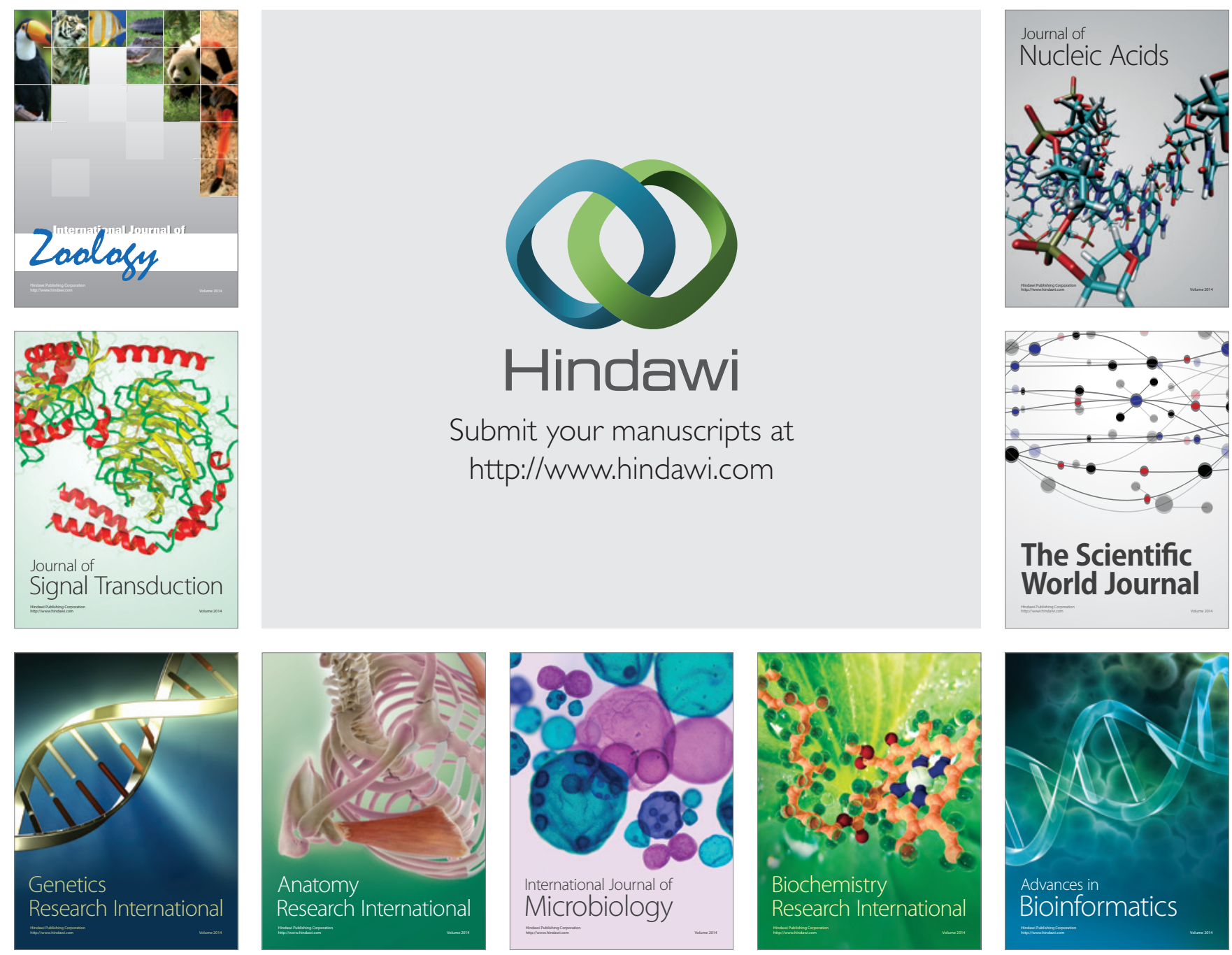

The Scientific World Journal
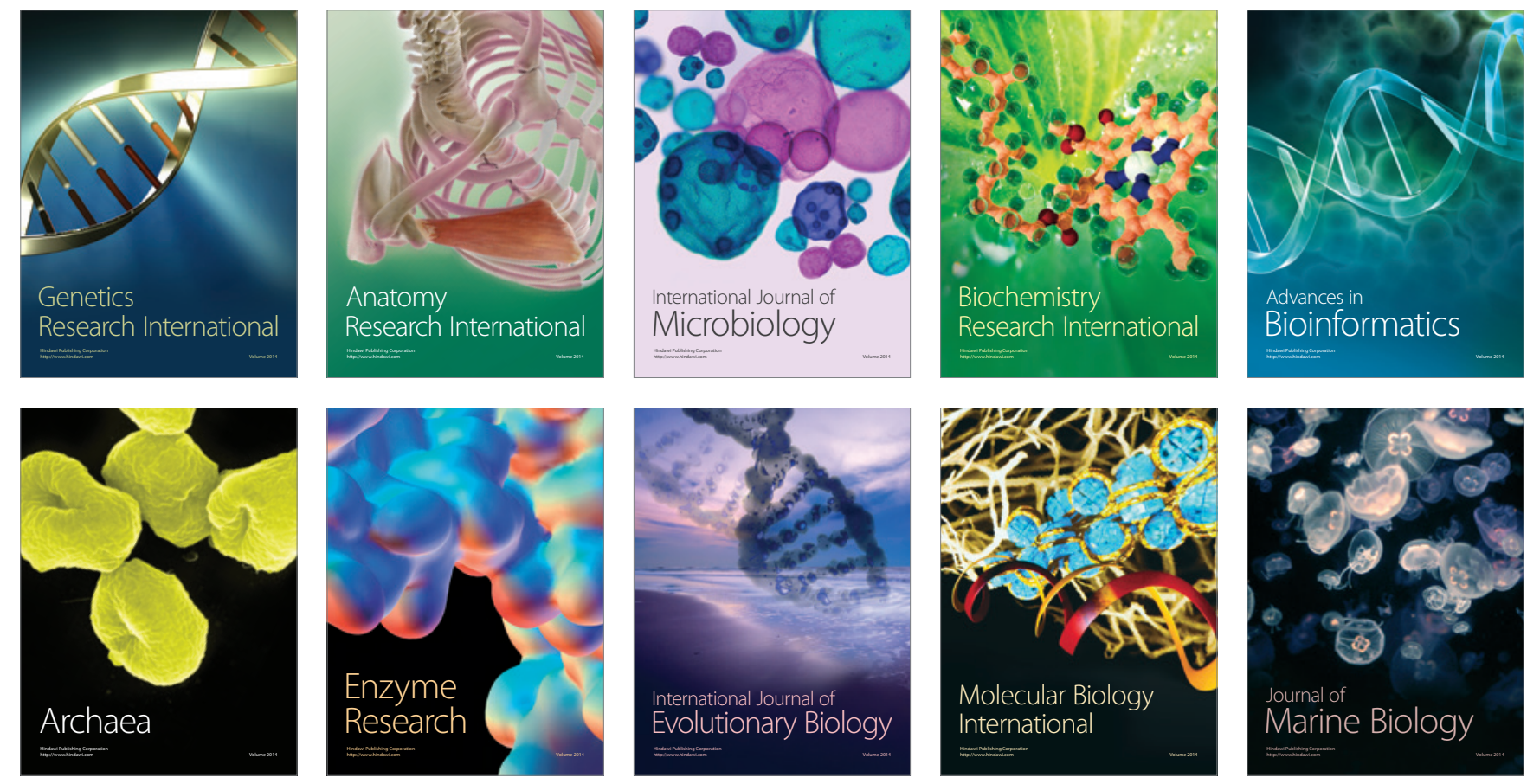